
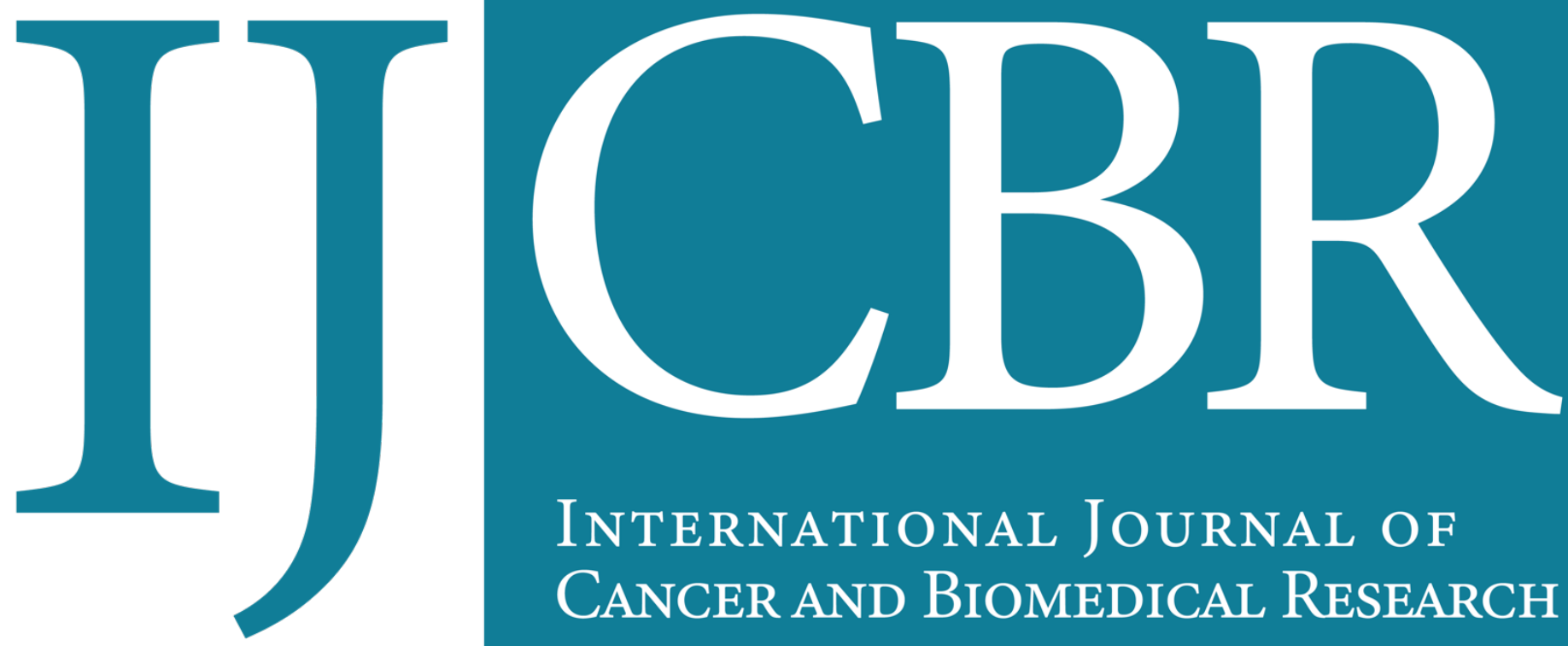

INTERNATIONAL JOURNAL OF CANCER AND BIOMEDICAL RESEARCH

https://jcbr.journals.ekb.eg

Editor-in-chief

Prof. Mohamed Labib Salem, PhD

CD44 and p53 c0-expression in high grade, muscle invasive bladder urothelial carcinoma with and without schistosomiasis

Rehab Sharaf El Deen, Osama Mohamed Sayed and Wesam Ismail Moustafa 


\title{
CD44 and p53 co-expression in high grade, muscle invasive bladder urothelial carcinoma with and without schistosomiasis
}

\author{
Rehab Sharaf El Deen ${ }^{1}$, Osama Mohamed Sayed ${ }^{2}$ and Wesam Ismail Moustafa ${ }^{1}$ \\ ${ }_{1}^{1}$ Pathology Department, Faculty of Medicine, Beni Suef University, Beni Suef, Egypt \\ ${ }^{2}$ Urology Department, Faculty of Medicine, Beni Suef University, Beni Suef, Egypt
}

\section{III \\ ABSTRACT}

Background \& Objectives: In Egypt, most patients diagnosed as urothelial carcinoma (UC) have high grade and muscle-invasive tumors that are commonly associated with schistosomal cystitis. CD44 and p53 may represent potential targets for anticancer treatment. We aimed to assess the expression of CD44 \& p53 and to determine their association in high grade, muscle-invasive tumors. Materials and Methods: Thirty four cystectomy cases with high-grade muscle-invasive UC were collected. Sections were stained for CD44 and p53 taking $10 \%$ and $20 \%$ positivity as cutoff values, respectively. Results: Median age was 60.5 years. Male/female ratio was 4:1. Fourteen cases were T2, 12 were T3, and 8 were T4. Nodal metastasis was evident in 8 cases. Conventional histology was seen in $38 \%$, followed by squamous differentiation in $24 \%$. Twenty patients had bilharzial cystitis. CD44 was positive in $8.8 \%$ of cases whereas p53 immunopositivity was noted in $76.5 \%$. CD44 and p53 expression had no statistical association with stage $(p=0.52$ and 0.97$)$ or bilharzial infestation ( $p=0.34$ and 0.16 ). There was no significant association between CD44 expression and that of $p 53, p=0.06$. Conclusion: High-grade muscle-invasive Schistosomal associated urothelial carcinomas are common, but with limited CD44 and p53 co-expression.

Keywords: Muscle invasive, urothelial carcinoma, P53, CD44, High grade

\section{ARTICLE INFO}

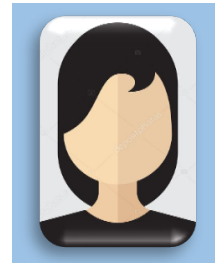

\section{Article history}

Received: August 19, 2020

Revised: November 28, 2021

Accepted: March 29, 2021

Correspondence to:

Dr Rehab Sharaf El Deen, MD

Pathology Department

Faculty of Medicine,

Beni Suef University,

Beni Suef, Egypt

Tel.: 01093876663

Email:

rehab.sharafeldeen@med.bsu.edu.eg

Editor-in-Chief: Prof. M.L. Salem, PhD - Article DOI: 10.21608/jcbr.2021.39890.1064

\section{INTRODUCTION}

Worldwide, infiltrating urothelial carcinoma of the bladder (UCB) represents the most common genitourinary malignancy after the prostate. Approximately, $25 \%$ of patients have muscleinvasive or metastatic disease at the time of initial diagnosis (Millis et al., 2015). Meanwhile, UCB is the most common variant of bladder cancer among Egyptians; the majority of diagnosed cases are high-grade and muscleinvasive tumors (Helal et al., 2015).

Urothelial carcinoma of the bladder is a molecularly heterogeneous tumor; characterized by mutations and losses of many genes regulating chromatin state, cell cycle control, and receptor kinase signaling (Kim et al., 2015). According to some studies, the cytogenetic and molecular genetic abnormalities are similar in schistosoma- associated and non-schistosoma-associated bladder carcinomas (Zaghloul, 2012).

High-grade urothelial tumors are known to be able to invade the muscle wall of the bladder and metastasize (Choudhary et al., 2015). Muscle invasive bladder carcinoma (MIBC) expresses high rates of mutation; as shown by TCGA data. These rates are interestingly similar to those of melanomas and non-small cell lung cancers (Inamura, 2018). Recent studies have divided high-grade muscle invasive UCs into distinct molecular subtypes which are luminallike and basal-like according to patterns of gene expression and tumor biology (Saito et al., 2018).

Management of MIBC is based on complete staging evaluation, laboratory investigations and reviewing tumor histopathologic characteristics (Chang et al., 2017). Even with radical cystectomy, radiotherapy and 
chemotherapy, it is believed that prognosis of UC patients depends on the genetic changes controlling its development and progression (Kim et al., 2015).

CD44 is a transmembrane glycoprotein surface receptor specific for hyaluronic acid. It represents one of the urothelial cancer stem cells (UCSCs) and has a role in cell migration, self-renewal, tumor adhesion, invasion and metastasis (Kobayashi et al., 2016). It has been suggested that the presence of bladder CSCs may be responsible for failure of adjuvant treatment and poor oncological control outcomes (Frang and Kitamura, 2018).

P53 is a tumor suppressor gene that is essential in regulating the cell cycle, apoptosis and DNA repair (Uehara and Tanaka, 2018; Bedeer et al., 2020). Mutations of TP53 have a fundamental role in the high-grade pathway of bladder carcinogenesis (Hodgson et al., 2017). Such mutations are commonly found in cases of MIBC, often with concurrent RB1 inactivation (Inamura, 2018). Therefore, mutated p53 protein may represent a potential target for anticancer treatment (Duffy et al., 2017).

This study aims to access the immunohistochemical expression of CD44 and p53 in high grade, muscle-invasive urothelial tumors, to correlate findings with available clinical data and the pathologic parameters, and to determine the relationship between both markers in such group of tumors.

\section{MATERIAL AND METHODS Case selection}

In this study, we included 34 patients diagnosed as non-metastatic high grade, muscle-invasive urothelial carcinoma; and treated by radical cystectomy. Formalin-fixed, paraffin-embedded blocks of patients were retrieved from the archives of Pathology Department, Faculty of Medicine, Beni-Suef University during the period between September 2017 and December 2019. Demographic data of patients were collected from the hospital records. Patients with no clinical data, inadequate tissue blocks or with another cancer diagnosis were excluded.

Hematoxylin- and Eosin-stained sections were obtained for evaluation and confirmation of tumor type and grading according to WHO classification of tumors of the urinary tract (Humphrey et al., 2016). Tumors were staged according to Tumor Node Metastasis TNM system of the American Joint Committee on Cancer, AJCC, $8^{\text {th }}$ edition (Amin et al., 2017). Associated bilharziasis, necrosis, lymph-vascular invasion (LVI), perineural invasion and lymph node metastases were also evaluated. Two sections of $4 \mu \mathrm{m}$ thickness, were immunostained; using a purified mouse monoclonal antibody against CD44 (1:50 dilution, cell mark, Rocklin, CA) and a purified mouse monoclonal antibody against p53, (1:50 dilution; Clone DO-7; Daco, USA).

Slides were deparaffinized and rehydrated by a series of washes with xylene and graded ethanol treatment. Boiling the slides in citrate buffer $(6 \mathrm{pH})$ was done for antigen retrieval, followed by cooling to room temperature. Sections were incubated with the primary antibodies overnight at room temperature followed by secondary antibody, DAB as a chromogen substrate, then Mayer's Hematoxylin as a counterstain.

\section{Interpretation of immunostains}

For CD44, sections were examined using light microscopy (Olympus model BX53) for brownish membranous staining pattern. The extent of positivity was scored according to the percentage of positively stained cells $(0,<10 \%$ of stained cells, $1=11-50 \%$ of stained cells, $2=$ $51-80 \%$ of stained cells and $3,>81 \%$ of stained cells) (Wu et al., 2017).

Nuclear brownish staining in sections treated for p53 antibody was considered positive. The percentage of immunopositive cells was calculated by counting at least 1000 tumor cells in areas of maximum positivity. Taking the cutoff value as $20 \%$, tumors were classified into three categories as immunonegative $0 \%,<20 \%$ as low, and $>20 \%$ as a high expression (Thakur et al., 2017).

\section{Statistical analysis}

Analysis of data was performed using IBM SPSS Statistics for Windows, version 23.0 (IBM Corp., Armonk, N.Y., USA). A Chi-square test was used to compare categorical variables with the status of $\mathrm{CD} 44$ and $\mathrm{p} 53$ expression. $\mathrm{P}<0.05$ was considered a statistically significant difference. 


\section{RESULTS}

In this study, the patients' age ranged between 48 and 73 years, with a mean age \pm standard deviation of $60 \pm 6.74$ years and a median of 60.5 years. The majority of patients were males $(n=27,79.41 \%)$ and only 7 cases were females; accounting for male: female ratio of 4:1Table 1 . Gross haematuria was the most common presenting symptom $(73.53 \%)$, followed by dysuria (14.71\%), irritative symptoms and clot retention (11.76\%). Fourteen $(41.18 \%)$ of the studied cases were T2, 12 (35.29\%) cases were T3, and $8(24 \%)$ cases were T4. Lymph node metastasis was evident in only 8 (23.53\%) cases; of which, 6 were $\mathrm{N} 1$ and the remaining 2 were N2 Table 2.

Conventional (pure) infiltrating urothelial carcinoma was the most frequent histologic type seen ( $n=13,38 \%)$, followed by UC with squamous differentiation ( $n=8,24 \%)$. Tumors with other divergent differentiation were also reported including glandular (4 cases), micropapillary (4 cases), sarcomatoid (3 cases), plasmacytoid (1 case) and small cell (1 case) morphologies. Evaluation of the associated histologic findings in the studied cases revealed bilharzial infestation in $20(59 \%)$ cases, necrosis in $17(50 \%)$ cases, perineural invasion in 12 (35\%) cases, and LVI in 11 (32\%) cases.

Regarding immunohistochemical results, p53 expression was found in 26 (76.5\%) cases; where 17 cases showed high expression and 9 cases showed low expression Figure 1A and 1B. On the other hand, CD44 was positive (+1score) in only $3(8.8 \%)$ cases; out of which 2 cases were T2 stage Figure $1 \mathrm{C}$ and $1 \mathrm{D}$. Both CD44 and p53 expression showed an insignificant statistical association with tumor stage $(p=0.52$ and 0.97 , respectively) Table 3 and 4 . Similarly, CD44 as well as p53 expression, did not show a statistical relationship with any of the recorded histologic findings. Although there was only one case that showed CD44 positive staining among the 26 positive $p 53$ cases, the difference did not reach statistical significance $(p=0.06)$ Table 5 .

\section{DISCUSSION}

In practice, advanced MIBCs present with poor prognosis and require aggressive management, such as radical cystectomy. Many immunohistochemical markers have been suggested for further risk stratification for such tumors, but none of these markers has been adapted in the current treatment guidelines (Wang et al., 2019).

This study showed that high-grade muscleinvasive urothelial carcinomas are common in the older age group (most patients were $\geq 60$ years old) with a significant male predominance. Almost similar results were reported by Gupta et al., 2009 and Leivo et al., 2016. However, different results were noticed by Wang et al., 2019 who included 91 patients with median age: 67 years and male-to-female ratio: 2.37:1.

Regarding the histology, we found that pure infiltrating urothelial carcinoma was the most common histologic type (38\%), then, tumors with squamous differentiation (24\%), glandular and micropapillary features represented $12 \%$, each. A descriptive study performed by Sasikumar et al., 2016 reported quite similar frequency where pure infiltrating urothelial carcinoma represented $88 \% \quad(105 / 118)$, squamous differentiation $9.3 \% \quad(11 / 118)$, glandular and micropapillary $0.8 \%$ (1/118), each. In our study, 3 cases (staged as T2 and T3) showed positive immunoreactivity for CD44. This result is quite close to Yıkılmaz et al., 2016 who collected 82 cases; 2/9 muscle-invasive tumors (stage, pT2) showed positive CD44 expression. On the other hand, Senol et al., 2015a reported that CD44 expression was negative in all patients with muscle-invasive urothelial carcinoma ( $n=38 / 163,23.3 \%$ ). This may be explained by differences in methods used in staining, evaluation and scoring.

Moreover, we found that the expression of CD44 has no statistical correlation with any pathological parameters. This finding was the same as Senol et al., 2015a and Haceka et al., 2020. We noticed positive p53 expression in $76.5 \%(n=26)$ of cases. This result was in concordance with a study by Venyo et al., 2010 where 24 (77.4\%) out of 31 muscle-invasive tumors were positive for $\mathrm{p} 53$. In contrast, less frequent rates of expression were found in studies by Compérat et al., 2006 (72\%, $n=41 / 57$ cases) and Senol et al., 2015b (64.7\%, $n=22 / 34$ cases). 
Table 1. Demographic data distribution in the studied cases

\begin{tabular}{|c|c|c|c|c|c|}
\hline & & Count & $\%$ & Mean $\pm S D$ & Median \\
\hline \multirow{3}{*}{ Age } & $<60$ & 13 & $38.24 \%$ & \multirow{3}{*}{$60 \pm 6.74$} & \multirow{3}{*}{60.5} \\
\hline & $\geq 60$ & 21 & $61.76 \%$ & & \\
\hline & Total & 34 & $100 \%$ & & \\
\hline \multirow{3}{*}{ Gender } & Male & 27 & $79.41 \%$ & & \\
\hline & Female & 7 & $20.59 \%$ & & \\
\hline & Total & 34 & $100 \%$ & & \\
\hline
\end{tabular}

Table 2. Pathological tumor (pT) stage and regional lymph node (pN) status in the studied cases

\begin{tabular}{|c|c|c|c|c|}
\hline \multicolumn{3}{|c|}{ Stage } & Count & $\%$ \\
\hline \multirow{4}{*}{$\mathrm{N}$} & \multicolumn{2}{|l|}{ T2 } & 14 & $41.18 \%$ \\
\hline & \multicolumn{2}{|l|}{ T3 } & 12 & $35.29 \%$ \\
\hline & \multicolumn{2}{|l|}{ T4 } & 8 & $23.53 \%$ \\
\hline & \multicolumn{2}{|c|}{ Total } & 34 & $100 \%$ \\
\hline \multirow{4}{*}{ P } & Negative & NO & 26 & $76.47 \%$ \\
\hline & \multirow{2}{*}{ Positive } & N1 & 6 & $17.65 \%$ \\
\hline & & N2 & 2 & $5.88 \%$ \\
\hline & \multicolumn{2}{|l|}{ Total } & 34 & $100 \%$ \\
\hline
\end{tabular}

All included patients were non-metastatic (M0)

Table 3. The relation between CD44 and tumor pathologic stage

\begin{tabular}{|c|c|c|c|c|c|}
\hline \multicolumn{2}{|c|}{ Stage } & \multicolumn{2}{c|}{ CD44 Expression } & \multirow{2}{*}{ Total } & \multirow{2}{*}{ P value } \\
\cline { 1 - 5 } T2 & Count & 12 & 2 & 14 & \\
\cline { 2 - 5 } & $\%$ & $85.7 \%$ & $14.3 \%$ & $100.0 \%$ & \multirow{2}{*}{0.52} \\
\hline \multirow{2}{*}{ T3 } & Count & 11 & 1 & 12 & \\
& $\%$ & $91.7 \%$ & $8.3 \%$ & $100.0 \%$ & \multirow{2}{*}{0.52} \\
\multirow{2}{*}{ T4 } & Count & 8 & 0 & 8 & \\
\cline { 2 - 5 } & $\%$ & $100.0 \%$ & $0.0 \%$ & $100.0 \%$ & \\
\multirow{2}{*}{ Total } & Count & 31 & 3 & 34 & \\
& $\%$ & $91.2 \%$ & $8.8 \%$ & $100.0 \%$ & \\
\hline
\end{tabular}

Table 4. The relation between p53 and tumor pathologic stage

\begin{tabular}{|c|c|c|c|c|c|}
\hline \multirow{2}{*}{\multicolumn{2}{|c|}{ Stage }} & \multicolumn{2}{|c|}{ p53 Expression } & \multirow{3}{*}{$\begin{array}{c}\text { Total } \\
14\end{array}$} & \multirow{2}{*}{ P Value } \\
\hline & & Positive & Negative & & \\
\hline \multirow{2}{*}{$\mathrm{T} 2$} & Count & 11 & 3 & & \multirow{7}{*}{0.97} \\
\hline & $\%$ & $78.6 \%$ & $21.4 \%$ & $100.0 \%$ & \\
\hline \multirow{2}{*}{ T3 } & Count & 9 & 3 & 12 & \\
\hline & $\%$ & $75.0 \%$ & $25.0 \%$ & $100.0 \%$ & \\
\hline \multirow{2}{*}{$\mathrm{T} 4$} & Count & 6 & 2 & 8 & \\
\hline & $\%$ & $75.0 \%$ & $25.0 \%$ & $100.0 \%$ & \\
\hline Total & Count & 26 & 8 & 34 & \\
\hline
\end{tabular}

Table 5. The relation between CD44 expression and p53 expression in the studied cases

\begin{tabular}{|c|c|c|c|c|c|c|}
\hline \multicolumn{2}{|c|}{} & \multicolumn{2}{c|}{$\begin{array}{c}\text { CD44 Expression } \\
\text { negative }\end{array}$} & \multirow{2}{*}{ positive } & Total & \multirow{2}{*}{ p value } \\
\hline \multirow{3}{*}{$\begin{array}{c}\text { p53 } \\
\text { expression }\end{array}$} & \multirow{2}{*}{ Positive } & Count & 25 & 1 & 26 & \\
\cline { 3 - 7 } & & $\%$ & $96.2 \%$ & $3.8 \%$ & $100.0 \%$ & \\
\cline { 3 - 7 } & \multirow{2}{*}{ Negative } & Count & 6 & 2 & 8 & \multirow{2}{*}{0.06} \\
\cline { 3 - 7 } & & $\%$ & $75.0 \%$ & $25.0 \%$ & $100.0 \%$ & \\
\hline \multicolumn{2}{|c|}{ Total } & Count & 31 & 3 & 34 & \\
\cline { 3 - 7 } & & $\%$ & $91.2 \%$ & $8.8 \%$ & $100.0 \%$ & \\
\hline
\end{tabular}




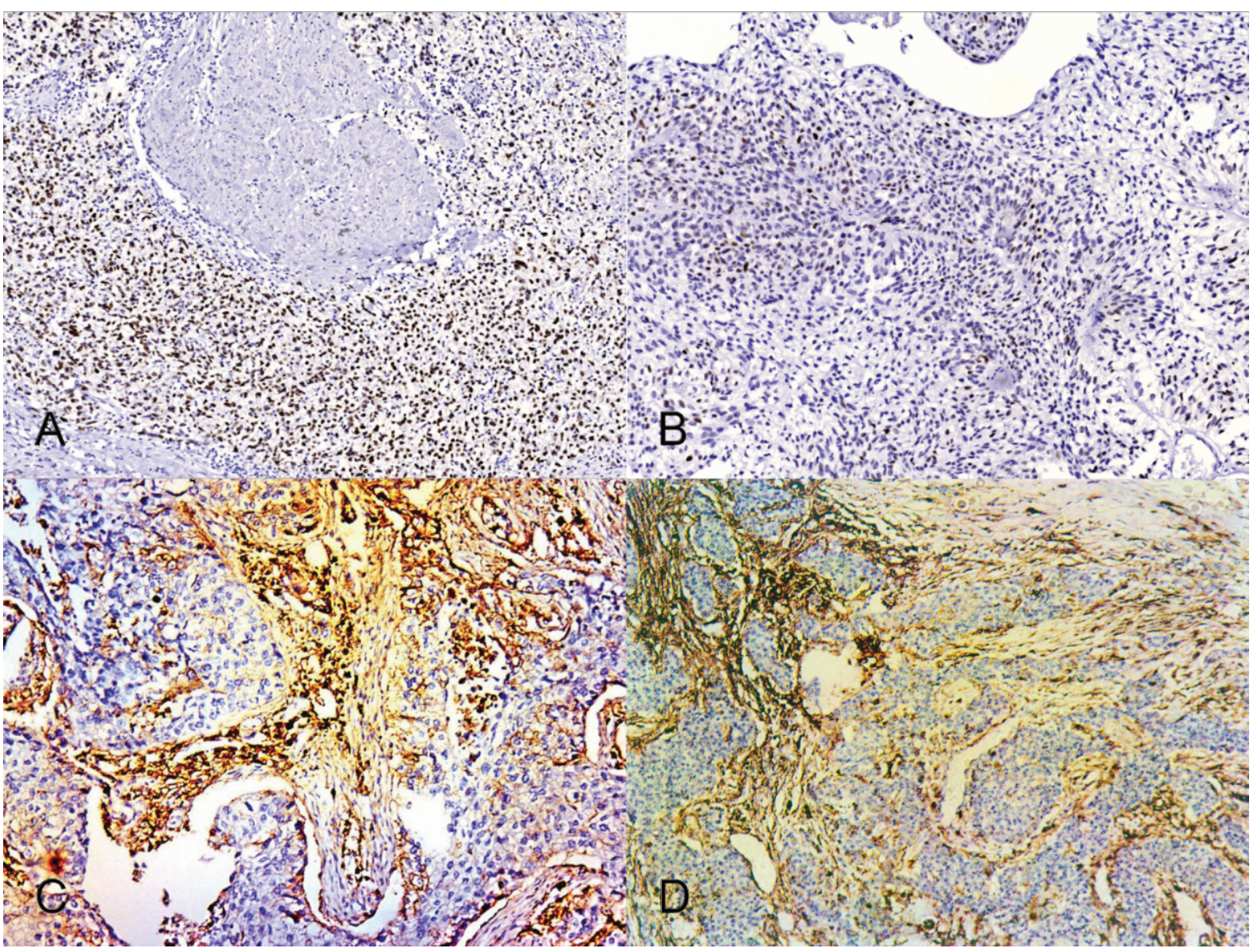

Figure 1. P53 and CD44 expression in muscle-invasive tumors: A) Strong diffuse nuclear expression of p53 in high-grade urothelial carcinoma (pT3) (IHC 1 x100). B) High-grade urothelial carcinoma (pT2) showing low nuclear expression of p53 in less than $20 \%$ of tumor cell nuclei (IHC, x100). C) Positive CD44 membranous immunoreactivity (+1 score) in urothelial carcinoma (pT2) (IHC, x200). D) High grade infiltrating urothelial carcinoma showing negative CD44 immunoreactivity (IHC, x200). ${ }^{1} \mathrm{HC}$ : immunohistochemistry.

Additionally, the higher frequency rate of expression was reported by Chen et al., 2019 $(86.7 \%, n=13 / 15)$. Many studies have shown significant correlations between the invasiveness of UC and the immunohistochemical patterns of TP53 mutations when all stages were considered. But, there was no association between p53 overexpression and $\mathrm{pT}$ stage in our work, where only muscle-invasive tumors (pT2-4) were compared. A similar result was reported in the study of Lianes et al., 1998.

To our knowledge, there are a few studies that exclusively deal with muscle-invasive UCs and this study analyzes the relation between CD44 and p53 in such group of tumors. It showed no significant association between CD44 and p53 expression ( $p$ value $>0.05$ ). Though percentages are shown significance yet ' $P$ ' values did not yield significance because of the small group of patients encountered during our study. The limitation of this work is mainly the lack of follow-up and outcome data of patients.

Finally, we concluded that high-grade muscleinvasive schistosoma-associated urothelial carcinomas are common, specially, among elderly men with limited CD44 expression and increased p53 expression. However, there was no significant association between these two markers in our work. A wider scale study with more patients including follow-up data may prove a significant relationship and help us to use the optimal therapeutic strategies.

\section{CONFLICTS OF INTEREST}

All authors have approved this article and declare no conflicts of interest.

\section{FUND}

No fund was received for this work. 


\section{REFERENCES}

Amin MB, Edge S, Greene F, Byrd DR, Brook, RK, Washington MK, Gershenwald JE, Compton CC, Hess KR (2017). American Joint Committee on Cancer Staging Manual (AJCC, 8th edition). Springer International Publishing.

Bedeer A, El-Rashidy M, Elzayat S, Elsherif H. (2020). Evaluation of the prognostic significance of P53 and Proliferating cell nuclear antigen (PCNA) in laryngeal squamous cell carcinoma. International Journal of Cancer and Biomedical Research, 4(3):169-176.

Chang SS, Bochner BH, Holzbeierlein JM (2017). Treatment of Non-Metastatic Muscle-Invasive Bladder Cancer: AUA/ASCO/ASTRO/SUO Guideline. Journal of Urology, 198(3):552-559.

Chen L, Liu Y, Zhang Q, Zhang M, Han X, Li Q, Xie T, Wu $Q$, Sui $X$ (2019). p53/PCDH17/Beclin-1 Proteins as Prognostic Predictors for Urinary Bladder Cancer. Journal of Cancer, 10(25): 6207-6216.

Choudhary D, Hegde P, Voznesensky O, Choudhary S, Kopsiaftis S, Claffey KP, Pilbeam CC, Taylor JA (2015). Increased expression of L-selectin (CD62L) in high-grade urothelial carcinoma: A potential marker for metastatic disease. Urologic Oncology, 33(9):387.e17-27.

Compérat E, Camparo P, Haus R, Chartier-Kastler E, Bart S, Delcourt A, Houlgatte A, François R, Capron F, Vieillefond A (2006). Immunohistochemical expression of p63, p53 and MIB-1 in urinary bladder carcinoma. A tissue microarray study of 158 cases. Virchows Archiv: an international journal of pathology, 448(3):319-324.

Duffy MJ, Synnott NC, Crown J (2017). Mutant p53 as a target for cancer treatment. European Journal of Cancer, 83:258-265.

Frang D, Kitamura H (2018). Cancer stem cells and epithelial-mesenchymal transition in urothelial carcinoma: Possible pathways and potential therapeutic approaches. International Journal of Urology, 25(1):7-17.

Gupta P, Jain M, Kapoor R, Muruganandham K, Srivastava A, Mandhani A (2009). Impact of age and gender on the clinicopathological characteristics of bladder cancer. Indian Journal of Urology, 25(2):207-210.

Haceka J, Brisudab A, Babjukb M, Zamecnika J (2020). Expression of cancer stem cells markers in urinary bladder urothelial carcinoma and its precursor lesions. Biomedical Papers of Med Faculty of the University of Palacky, Olomouc, Czechoslovakia.

Hodgson A, Xu B, Downes MR (2017). p53 immunohistochemistry in high-grade urothelial carcinoma of the bladder is prognostically significant. Histopathology, 71(2):296-304.

Humphrey PA, Moch H, Cubilla AL, Ulbright TM, Reuter VE (2016). The 2016 WHO Classification of Tumours of the Urinary System and Male Genital Organs-Part B: Prostate and Bladder Tumours. European Urology, 70(1):106-119.

Inamura K 2018. Bladder Cancer: New Insights into Its Molecular Pathology. Cancers (Basel), 10(4):100.

Kim PH, Cha EK, Sfakianos JP, Iyer G, Zabor EC, Scott SN, Ostrovnaya I, Ramirez R, Sun A, Shah R, Yee $A M$, Reuter VE, Bajorin DF, Rosenberg JE, Schultz N, Berger MF, Al-Ahmadie HA, Solit DB, Bochner BH 2015. Genomic predictors of survival in patients with high-grade urothelial carcinoma of the bladder. European Urology, 67(2):198-201.

Kobayashi K, Matsumoto H, Matsuyama H, Fujii N, Inoue R, Yamamoto Y, Nagao K 2016. Clinical significance of CD44 variant 9 expression as a prognostic indicator in bladder cancer. Oncology Report, 36(5):2852-2860.

Leivo MZ, Elson PJ, Tacha DE, Delahunt B, Hansel DE (2016). A combination of p40, GATA-3 and uroplakin II shows utility in the diagnosis and prognosis of muscle-invasive urothelial carcinoma. Pathology, 48(6):543-549.

Lianes $\mathrm{P}$, Charytonowicz E, Cordon-Cardo C, Fradet $\mathrm{Y}$, Grossman HB, Hemstreet GP, Waldman FM, Chew K, Wheeless LL, Faraggi D (1998). Biomarker study of primary non metastatic versus metastatic invasive bladder cancer. National Cancer Institute Bladder Tumor Marker Network. Clinical Cancer Research, 4(5):1267-1271.

Millis SZ, Bryant D, Basu G, Bender R, Vranic S, Gatalica Z, Vogelzang NJ (2015). Molecular profiling of infiltrating urothelial carcinoma of bladder and non-bladder origin. Clinical Genitourinary Cancer, 13(1):37-49.

Saito R, Smith CC, Utsumi T, Bixby LM, Kardos J, Wobker SE, Stewart KG, Chai S, Manocha U, Byrd KM, Damrauer JS, Williams SE, Vincent BG, Kim WY (2018). Molecular Subtype-Specific Immunocompetent Models of High-Grade Urothelial Carcinoma Reveal Differential Neoantigen Expression and Response to Immunotherapy. Cancer Research, 78(14):3954-3968.

Sasikumar S, Wijayarathna KSN, Karunaratne KAMS, Gobi U, Pathmeswaran A, Abeygunasekera AM (2016). Pathological Characteristics of Primary Bladder Carcinoma Treated at a Tertiary Care Hospital and Changing Demographics of Bladder Cancer in Sri Lanka. Advances in Urology, 2016(3):1-6. 
Senol S, Yildırım A, Akalin I, Uruç F, Çobanoğlu B, Yilmaz S, Ceyran B, Kösemetin D, Ece D, Aydın A (2015a). Relation of stem cell markers ALDH1 and CD44 with clinicopathological factors in urothelial carcinomas of urinary bladder. International Journal of Clinical and Experimental Medicine, 8(3):4195-4203.

Senol S, Yildirim A, Ceyran B, Uruc F, Zemheri E, Ozkanli S, Akalin I, Ulus I, Caskurlu T, Aydin A (2015b). Prognostic significance of survivin, $\beta$ catenin and p53 expression in urothelial carcinoma. Bosnian Journal of Basic Medical Sciences, 15(4):7-14.

TEA Helal, MI Salman, SS Ezz-Elarab (2015). Pathology-based cancer registry 2001-2010. Ain-Shams Faculty of Medicine, Cairo, Egypt.

Thakur B, Kishore S, Dutta K, Kaushik S, Bhardwaj A (2017). Role of p53 and Ki-67 immunomarkers in carcinoma of urinary bladder. Indian Journal of Pathology \& Microbiology, 60(4):505-509.

Uehara I, Tanaka N (2018). Role of p53 in the regulation of the inflammatory tumor microenvironment and tumor suppression. Cancers (Basel), 10(7):219.
Venyo A, Greenwood H, Maloney D (2010). The Expression of P53 in human urothelial carcinoma. Web med Central Urology, 1(11)

Wang QH, Ji ZG, Li HZ, Fan H, Chen ZG, Shi BB, Fang Y (2016). Clinicopathologic Comparison of Urothelial Bladder Carcinoma in Young and Elder Patients. Pathology Oncology Research, 22(1):67-70.

Wu CT, Lin WY, Chang YH, Chen WC, Chen MF (2017). Impact of CD44 expression on radiation response for bladder cancer. Jouranl of Cancer, 8(7):1137-1144.

Yikilmaz TN, Dirim A, Ayva ES, Ozdemir H, Ozkardes $H$ (2016). Clinical Use of Tumor Markers for the Detection and Prognosis of Bladder Carcinoma: A Comparison of CD44, Cytokeratin 20 and Survivin. Urology Journal, 13(3):2677-2683.

Zaghloul MS (2012). Bladder cancer and Schistosomiasis. Journal of the Egyptian National Cancer Institute, 24(4): 151-159. 